OPEN

SUBJECT AREAS:

NANOSCIENCE AND

TECHNOLOGY

MATERIALS SCIENCE

Received

8 September 2014

Accepted

6 October 2014

Published

23 October 2014

Correspondence and requests for materials should be addressed to

S.J.I. (samuel. ippolito@rmit.edu.au) or S.K.B. (suresh. bhargava@rmit.edu.

au)

\section{Gold nanospikes based microsensor as a highly accurate mercury emission monitoring system}

Ylias M. Sabri', Samuel J. Ippolito', James Tardio', Vipul Bansal' , Anthony P. O'Mullane² \& Suresh K. Bhargava'

${ }^{1}$ Centre for Advanced Materials and Industrial Chemistry, School of Applied Sciences, RMIT University, GPO Box 2476V, Melbourne, VIC, Australia, 3001, '2 School of Chemistry, Physics and Mechanical Engineering, Queensland University of Technology, GPO Box 2434, Brisbane, Australia.

Anthropogenic elemental mercury $\left(\mathrm{Hg}^{0}\right)$ emission is a serious worldwide environmental problem due to the extreme toxicity of the heavy metal to humans, plants and wildlife. Development of an accurate and cheap microsensor based online monitoring system which can be integrated as part of $\mathrm{Hg}^{0}$ removal and control processes in industry is still a major challenge. Here, we demonstrate that forming Au nanospike structures directly onto the electrodes of a quartz crystal microbalance (QCM) using a novel electrochemical route results in a self-regenerating, highly robust, stable, sensitive and selective $\mathrm{Hg}^{0}$ vapor sensor. The data from a 127 day continuous test performed in the presence of volatile organic compounds and high humidity levels, showed that the sensor with an electrodeposted sensitive layer had $260 \%$ higher response magnitude, 3.4 times lower detection limit $\left(\sim 22 \mu \mathrm{g} / \mathrm{m}^{3}\right.$ or $\left.\sim 2.46 \mathrm{ppb}_{\mathrm{v}}\right)$ and higher accuracy $(98 \% \mathrm{Vs} 35 \%)$ over a Au control based QCM (unmodified) when exposed to a $\mathrm{Hg}^{0}$ vapor concentration of $10.55 \mathrm{mg} / \mathrm{m}^{3}$ at $101^{\circ} \mathrm{C}$. Statistical analysis of the long term data showed that the nano-engineered $\mathrm{Hg}^{0}$ sorption sites on the developed Au nanospikes sensitive layer play a critical role in the enhanced sensitivity and selectivity of the developed sensor towards $\mathrm{Hg}^{0}$ vapor.

T he urgency to develop accurate, reliable, durable and inexpensive alternatives to commercially available spectroscopy based elemental mercury $\left(\mathrm{Hg}^{0}\right)$ vapor sensors is ever growing given the recent United Nations Environmental Programme's (UNEP) Minamata Convention where 140 nations agreed on a legally binding mercury rule ${ }^{1,2}$. This is not surprising when an estimated 60,000 babies with mercury related diseases are born in the US alone each year because pregnant mothers are being exposed to mercury through their environmental surroundings or via consumption of contaminated food sources ${ }^{3,4}$. In order to reduce emissions, accurate, cheap and reliable online $\mathrm{Hg}^{0}$ monitoring technologies are imperative for providing feedback to industrial process control systems ${ }^{5}$. The commercially available instruments are typically based upon cold-vapor atomic absorption (CV-AAS), atomic fluorescence (AFS) or atomic emission (AES) spectroscopy techniques. Although these systems are able to detect mercury down to $0.5 \mathrm{ppt}\left(0.64 \mathrm{ng} / \mathrm{m}^{3}\right)$, the cross interference that occurs due to the presence of other gaseous species within many industrial process streams makes them unreliable as $\mathrm{Hg}^{0}$ vapor sensors within industries such as the mineral processing sector. These gaseous species include carbonyl containing volatile organic compounds (VOCs) such as benzene, toluene and acetone as well as non-condensable gases (i.e. $\mathrm{SO}_{2}, \mathrm{NO}_{2}, \mathrm{H}_{2} \mathrm{O}, \mathrm{O}_{3}$ ). These gas species absorb light at a wavelength of $253.7 \mathrm{~nm}$ which is the same spectral region as that of mercury therefore resulting in false positive output by the sensor ${ }^{6-9}$. The laborious sampling (i.e. Appendix K or Ontario Hydro) methods currently used and accepted by the US- Environmental Protection Agency (EPA) are expensive, require sample pre-treatment, using highly qualified operators and also provide no real-time data (typically with a 2 -week or more turnaround time) ${ }^{10}$. It is due to these shortcomings of the available detection methods that industries (i.e. mining, cement, coal and petroleum) around the world are actively pursuing alternative methods to measure $\mathrm{Hg}^{0}$ vapor in real time within their processes and emission stacks, ${ }^{5,10}$.

Here, we report for the first time the ability to measure $\mathrm{Hg}^{0}$ vapor present in a synthetic industrial effluent (containing various VOCs, humidity and ammonia) over a 127 day testing period. Furthermore, the synthesis of our $\mathrm{Hg}^{0}$ selective Au nanostructures directly onto the quartz crystal microbalance (QCM) electrodes has allowed for $\mathrm{Hg}^{0}$ vapor concentration to be reported within 2-hours rather than 2-weeks. Additionally we report selfregeneration (recovery) of the sensor after a sensing event and its ability to operate continuously at a temperature 


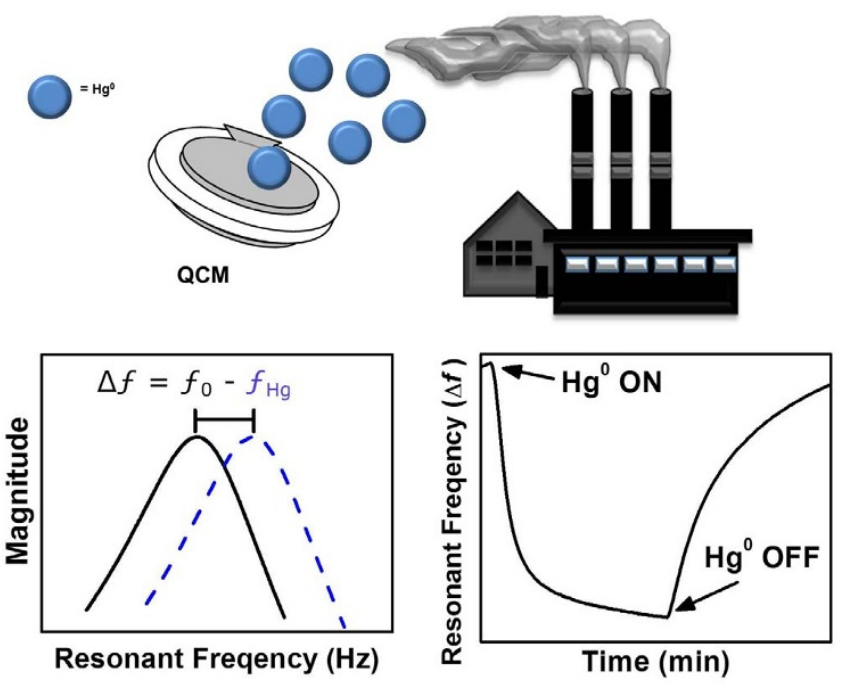

Figure $1 \mid$ Schematic representation of the principle of QCM based $\mathrm{Hg}^{\mathbf{0}}$ vapor sensor.

of $101^{\circ} \mathrm{C} \pm 1{ }^{\circ} \mathrm{C}$ for long periods of time making it relevant for most industrial processes. Significantly, we have demonstrated a solid state $\mathrm{Hg}^{0}$ sensor that is reliable and accurate which can potentially be used in harsh industrial process conditions to monitor $\mathrm{Hg}^{0}$ in stack gas and operate as part of $\mathrm{Hg}^{0}$ emissions control system.

\section{Results and Discussion}

Surface characterization of the sensitive layer. Figure 1 illustrates the principle of the QCM based $\mathrm{Hg}^{0}$ vapor sensor. The technology relies on measuring the resonant frequency $\left(f_{0}\right)$ of the QCM upon exposure to the gas stream containing $\mathrm{Hg}^{0}$ vapor. As the sensitive gold layer on the QCM electrodes is exposed to $\mathrm{Hg}^{0}$ vapor, an amalgam is formed at the sensor surface which results in increased mass of the QCM electrodes. From Sauerbrey's equation ${ }^{11}$, a change in mass $(\Delta m)$ of the electrodes results in a proportional change in the resonant frequency $(\Delta f)$ of the QCM as;

$$
\Delta f=-S_{f} \Delta m,
$$

where $S_{f}$ represents the mass sensitivity. The QCM based microsensor in this study was modified by a novel electrodeposition process wherein $\mathrm{Pb}^{2+}$ ions were used as a shape-directing additive, resulting in the growth of well adhered, $\mathrm{Hg}^{0}$ selective Au nanostructures directly on the electrode surfaces of the QCMs. Figure 2a shows the SEM image of a control Au surface which was fabricated by depositing a $10 \mathrm{~nm}$ Ti adhesion layer and a $100 \mathrm{~nm}$ thick Au film (via e-beam evaporation) onto a quartz substrate to form the electrodes of the QCM. The SEM image clearly indicates a relatively flat surface with well-dispersed Au clusters. Figures $2 \mathrm{~b}$ to $2 \mathrm{j}$ show the representative SEM images of Au-coated QCM crystals after subsequent electrodeposition of $\mathrm{Au}$ from an electrolyte containing $6.9 \mathrm{mM} \mathrm{AuCl}_{4}{ }^{-}$ions and $0.47 \mathrm{mM} \mathrm{Pb}^{2+}$ ions at a constant deposition potential of $0.05 \mathrm{~V}$ for a period of $100 \mathrm{sec}$ (Figure 2b), $200 \mathrm{sec}$ (Figure 2c), $300 \mathrm{sec}$ (Figure 2d), $400 \mathrm{sec}$ (Figure 2e), $500 \mathrm{sec}$ (Figure 2f), $600 \mathrm{sec}$ (Figure 2g), $700 \mathrm{sec}$ (Figure $2 \mathrm{~h}$ ) and $800 \mathrm{sec}$ (Figure 2i), respectively. It can be observed from the SEM images that during the initial phase of $\mathrm{Au}$ electrodeposition, pre-existing $\mathrm{Au}$ nanoclusters of the e-beamevaporated gold film (Figure 2a) act as nucleation centers for the growth of Au nanoparticles (Figure 2b), which then start growing outwardly in a network-like structure of Au nanospikes as the reaction continues for $200 \mathrm{sec}$ (Figure 2c). When the electrodeposition of $\mathrm{Au}$ is continued for 300, 400 and $500 \mathrm{sec}$, the whole surface of the QCM crystal is observed to be uniformly covered with
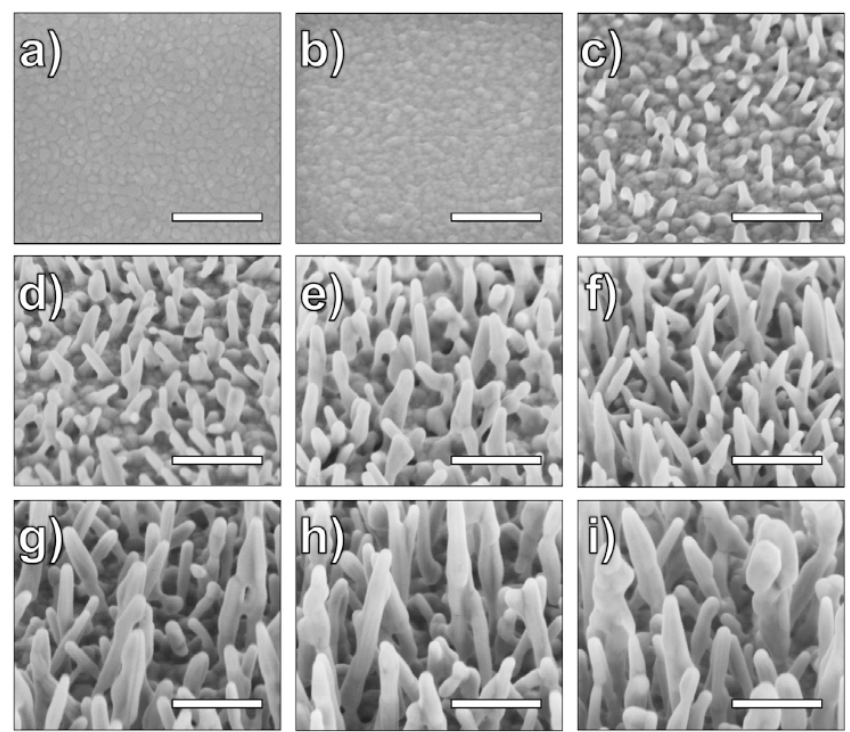

Figure 2 $\mid$ SEM micrographs of (a) $100 \mathrm{~nm}$ thick Au film (Au-control) e-beam evaporated on to a QCM followed by electrodeposition of Au on the surface in the presence of $\mathrm{Pb}^{2+}$ ions for a period of (b) $100 \mathrm{sec}$, (c) $200 \mathrm{sec}$, (d) $300 \mathrm{sec}$, (e) $400 \mathrm{sec}$, (f) $500 \mathrm{sec}$, (g) $600 \mathrm{sec}$, (h) $700 \mathrm{sec}$ and (i) $800 \mathrm{sec}$. The scale bars correspond to $500 \mathrm{~nm}$.

well-defined Au nanospikes having prismatic tapering ends as shown in Figures 2d, 2e and 2f, respectively. A further increase in electrodeposition time to 600,700 and $800 \mathrm{sec}$ results in larger nanospikes, with the appearance of sharp nodular structures as shown in Figures 2g, $2 \mathrm{~h}$ and 2i, respectively. Angular $40^{\circ}$ side-view SEM imaging of the $600 \mathrm{sec}$ sample edge indicates that these nanospikes are $\sim 1 \mu \mathrm{m}$ in length with a base thickness of $\sim 50 \mathrm{~nm}$ and tip thickness of $\sim 10 \mathrm{~nm}$ (Supporting information, Figure S1). Notably, both sides of the QCM crystal showed an extremely uniform coverage of the aforementioned structures, as can be seen in a lowermagnification SEM image of the nanospikes obtained after $600 \mathrm{sec}$ of electrodeposition (Supporting information, Figure S2).

The electrochemically active surface area (ESA) of the Au control and each of the electrodeposited $\mathrm{Au}$ nanospikes was determined using the method developed by Rand and Woods ${ }^{12}$. Figure 3 a shows an example cyclic voltammogram that was taken for each of the electrodeposited surfaces, while Figure $3 \mathrm{~b}$ shows the potential region used to calculate the charge required for the reduction of one monolayer of oxide formed on the surfaces during a cyclic voltammogram (recorded for $\mathrm{Au}$ in $1 \mathrm{M} \mathrm{H}_{2} \mathrm{SO}_{4}$ ) which can be correlated with the ESA. An increase in the cathodic peak was observed at $0.93 \mathrm{~V}$ which is indicative of the removal of oxide (formed in the forward sweep) from the electrode surface. The onset for oxide formation for the electrodeposited nanospikes is observed to occur at a lower potential than that of the Au-control electrode indicating that gold nanostructures were formed. The appearance of the shoulder at ca. $1.05 \mathrm{~V}$ prior to the main oxide formation process confirms that the nanospikes have active surface defect sites $^{13}$ which is reported to have high affinity towards $\mathrm{Hg}^{0}$ vapor ${ }^{14-16}$. As expected, the ESA of the Au nanospikes increased with increasing deposition times as shown in Figure 3c.

The XRD analysis of the electrodeposited samples shown in Figure $4 \mathrm{a}$ reveals the preferential growth of the face centered cubic (fcc) Au nanospikes along the (200) crystallographic plane (Figure $4 \mathrm{~b}$ ), evident from the plot representing the ratios of the (111) and (200) diffraction peaks at different electrodeposition times (Figure 4c). Interestingly, each sample has a greater (111): (200) ratio than the standard Au JCPDS file reference $(>17 \text { versus } 3)^{17}$ with the Au control film having a ratio above 120. A significant increase of the 


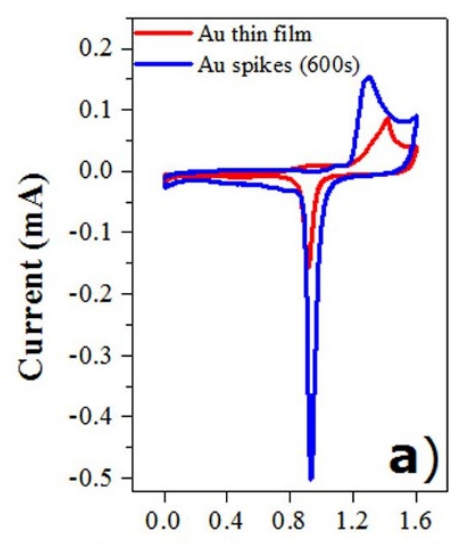

Potential (V) vs Ag/AgCl
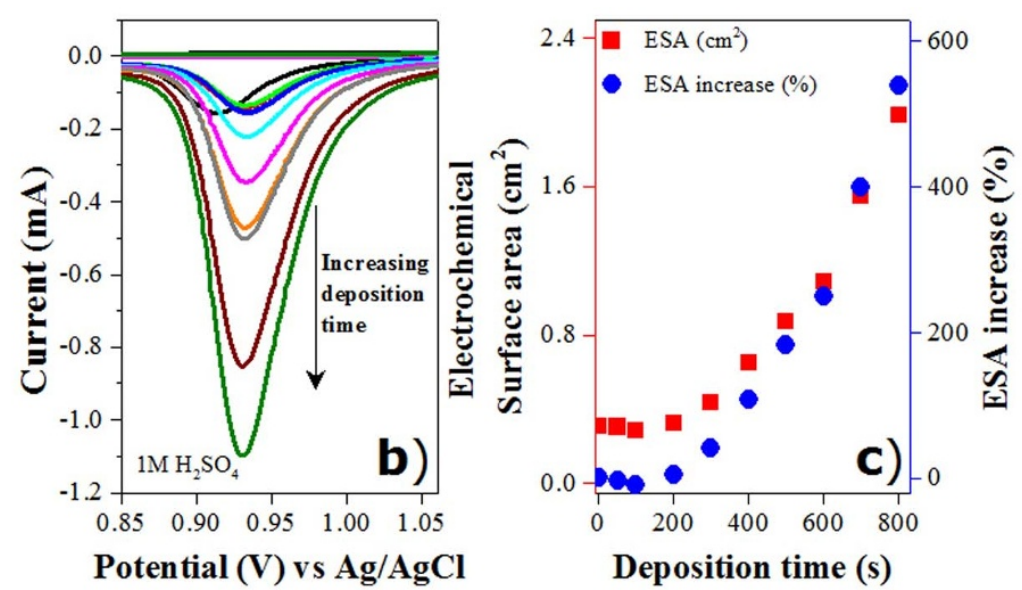

Figure $3 \mid$ (a) Linear sweep voltammograms (LSVs) obtained at $100 \mathrm{mV} \mathrm{s}^{-1}$ in $1 \mathrm{M} \mathrm{H}_{2} \mathrm{SO}_{4}$ solution for the Au control and electrodeposited Au nanospikes and (b) for the reduction of the monolayer oxide formed on these surfaces during a cyclic voltammogram recorded for Au in $1 \mathrm{M} \mathrm{H}_{2} \mathrm{SO}_{4}$ and which was used to calculate the electrochemical surface area (ESA) and (c) calculated ESA increase for each sample using their respective LSV. The mechanical surface area of each substrate was $0.32 \mathrm{~cm}^{2}$.

(200) peak is observed as the reaction progresses. However the decrease in the (111): (200) ratio indicates that the growth of these $\mathrm{Au}$ nanospikes shaped structures may be due to the preferential affinities of the $\mathrm{Pb}^{2+}$ and $\mathrm{AuCl}_{4}{ }^{-}$ions towards the different crystallographic facets. That is, $\mathrm{Pb}^{2+}$ ions is reported to bind more strongly to the $\mathrm{Au}(110)$ and (100) facets ${ }^{16,18}$ over the (111) facet while $\mathrm{AuCl}_{4}{ }^{-}$ ions bind most strongly to the (111) facets ${ }^{19}$. It is postulated that this differing affinities towards the different Au facets during the growth period is the result of the formation of pure gold nanospikes. That is, although $\mathrm{Pb}^{2+}$ ions were employed as a shape-directing additive in our study, characterization of the structures using energy-dispersive
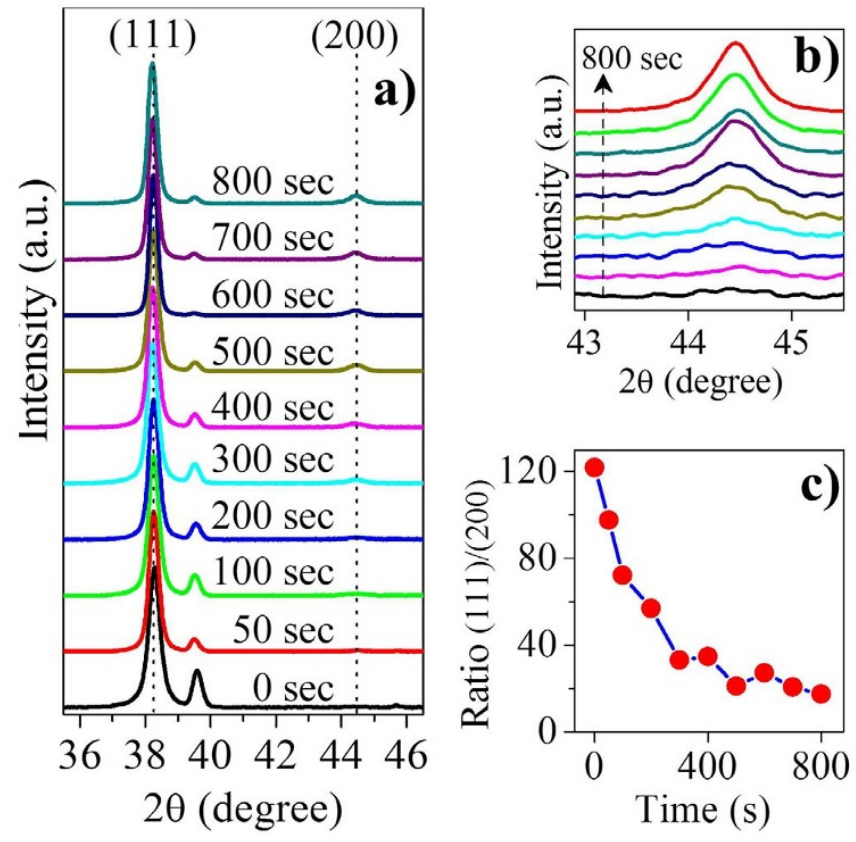

Figure $4 \mid$ Sequential series of XRD patterns of of electrodeposited Au in the presence of $\mathrm{Pb}^{2+}$ ions for a period of 0 (Au-control), 50, 100, 200, 200, $400,500,600,700$ and 800 seconds over a range of (a) $36^{\circ}<\theta<46^{\circ}$ and (b) close up look of the (200) plane in the rage of $43^{\circ}<\theta<45^{\circ}$ demonstrating the preferential growth of face centered cubic (fcc) Au nanospikes along (200) crystallographic plane which is confirmed in (c) showing the reduction in the ratio of $(111) /(200)$ peaks with increasing electrodeposition time.
X-ray (EDX) and X-ray photoelectron spectroscopy (XPS) both failed to detect the presence of $\mathrm{Pb}$ ions on the electrodeposited surfaces (Supporting information, Figure S3). The absence of $\mathrm{Pb}^{2+}$ corroborate well with our recent work, wherein during gold premonolayer oxidation studies an in situ galvanic replacement of metallic $\mathrm{Pb}\left(\mathrm{Pb}^{0}\right)$ from $\mathrm{AuCl}_{4}{ }^{-}$ions was observed during the course of $\mathrm{Au}$ electrodeposition process ${ }^{20}$. In this study, it is possible that $\mathrm{Pb}^{2+}$ ions, which are initially bound to the $\mathrm{Au}(110)$ and (100) facets, get reduced on these facets in the form of $\mathrm{Pb}^{0}$. The system however energetically allows galvanic replacement of $\mathrm{Pb}^{0}\left(\right.$ to $\mathrm{Pb}^{2+}$ ) with $\mathrm{Au}^{3+}$ ions $\left(\right.$ to $\mathrm{Au}^{0}$ ) present in the electrolyte to occur since the deposition potential used was above that for bulk $\mathrm{Pb}$ and therefore leaving no $\mathrm{Pb}$ on the surface of the Au nanospikes.

Sensor performance. The QCM transducer, once excited, resonates at $f_{0}$, which can be described by a simple mass-spring-dashpot system $^{21}$. This vibration mode $\left(f_{0}\right)$ is associated to the quality factor Q, defined as $Q=f_{0} / F W H M$, where FWHM is the full width at half mazximum and is related to the sharpness of the resonant peak. The ultimate sensing resolution is achieved by employing the transducer which has a high Q factor ${ }^{22}$. Therefore the QCM's Q factor was considered as a key figure of merit when selecting them for $\mathrm{Hg}$ vapor sensing experiments. The Au nanospikes based QCM formed following $600 \mathrm{sec}$ deposition time was found to attain the highest amount of deposited Au while maintaining a high $\mathrm{Q}$ factor of 6500 while QCMs with Au electrodeposition periods $>600$ showed drastic drop in Q. Therefore, the QCM with electrodeposited gold for a period of 600s was chosen to be tested for $\mathrm{Hg}^{0}$ sensing experiments.

The Au nanospikes based QCM was tested against that of the $\mathrm{Au}$ control QCM (both with a $100 \mathrm{~nm}$ e-beam evaporated Au electrode layer) at five different $\mathrm{Hg}^{0}$ concentrations $\left(\mathrm{C}_{1}=1.02 \mathrm{mg} / \mathrm{m}^{3}, \mathrm{C}_{2}=\right.$ $1.87 \mathrm{mg} / \mathrm{m}^{3}, C_{3}=3.65 \mathrm{mg} / \mathrm{m}^{3}, \mathrm{C}_{4}=5.70 \mathrm{mg} / \mathrm{m}^{3}$ and $\mathrm{C}_{5}=$ $10.55 \mathrm{mg} / \mathrm{m}^{3} \pm 0.05 \mathrm{mg} / \mathrm{m}^{3}$ ) and an operating temperature of $101^{\circ} \mathrm{C}$, the response of which are shown in Figure 5. This operating temperature was chosen following many preliminary experiments in order to reduce the effects of cross contamination from other interferent gas species when detecting $\mathrm{Hg}^{0}$ vapor while simultaneously reducing the effect of a morphology change that has been reported to occur over long periods of $\mathrm{Hg}^{0}$ exposure at high operating temperatures closer to $150^{\circ} \mathrm{C}^{23,24}$. Furthermore, the operating temperature of $101^{\circ} \mathrm{C}$ is very similar to that used when sampling trace amounts of $\mathrm{Hg}^{0}$ from industrial flue gas ${ }^{25}$ as well as being the temperature at which all $\mathrm{Hg}^{0}$ is collected by gold coatings in the diffusion screen (stainless steel mesh coated with $\mathrm{Au}$ ) experiments reported by others ${ }^{26}$. 


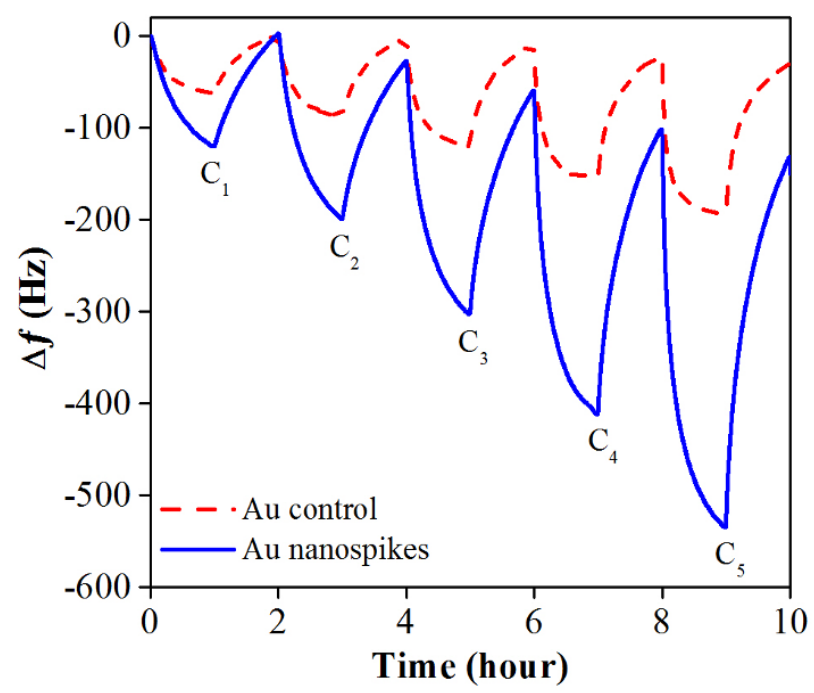

Figure 5 QCM sensor response of Au surfaces towards different $\mathrm{Hg}^{0}$ vapor concentrations $\left(\mathrm{C}_{1}=1.02 \mathrm{mg} / \mathrm{m}^{3}, \mathrm{C}_{2}=1.87 \mathrm{mg} / \mathrm{m}^{3}, \mathrm{C}_{3}=3.65 \mathrm{mg} /\right.$ $\mathrm{m}^{3}, \mathrm{C}_{4}=5.70 \mathrm{mg} / \mathrm{m}^{3}$ and $\left.\mathrm{C}_{5}=10.55 \mathrm{mg} / \mathrm{m}^{3}, \mathrm{C}_{1}=1.02 \mathrm{mg} / \mathrm{m}^{3}\right)$ at $101 \pm$ $1^{\circ} \mathrm{C}$ before (dotted curves) and after (solid curves) electrodeposition of $\mathrm{Au}$ nanospikes.

As can be seen by Figure 5, the nanospikes based QCM was observed to have a $260 \%$ response magnitude compared to that of the Au control based QCM towards $\mathrm{Hg}^{0}$ concentration of $10.55 \mathrm{mg} /$ $\mathrm{m}^{3}$ when operated at $101^{\circ} \mathrm{C}$. The ESA data presented in Figure 3 was used to normalize the sensor response magnitudes for their surface area. The normalized sensors response magnitudes from experiments conducted at near room temperature $\left(28^{\circ} \mathrm{C}\right)$ is presented in the supporting information (Figure S4). The data clearly demonstrates that the nanospikes' higher sensitivity $(>400 \%$ higher) relative to Au control was not just due to the increased surface area as a result of Au electrodeposition, but also due to formation of atomicscale features (i.e. steps and defect sites) introduced during the electrodeposition process (see Figure 3 discussions).

As well as having a higher sensitivity, the Au nanospikes based QCM was found to be superior in regards to the sensor response time, extent of recovery and detection limit towards $\mathrm{Hg}^{0}$ vapor over the Au control based QCM as calculated from the data presented in Figure 5 . The response time is usually measured as the $t_{90}$ parameter which is used within the sensor community to define the time required to obtain $90 \%$ of the response maximum for a given sensing event. The $\mathrm{t}_{90}$ of the $\mathrm{Au}$ control and nanospikes at $\mathrm{Hg}^{0}$ vapor concentration of $10.55 \mathrm{mg} / \mathrm{m}^{3}$ and operating temperature of $101^{\circ} \mathrm{C}$ was observed to be $31 \pm 3$ and $16 \pm 2$ minutes, respectively. The ratio of mercury desorption to sorption (i.e. extent of recovery) for both the $\mathrm{Au}$ control and nanospikes QCMs were found to be $>95 \%$. The detection limits were calculated (from Figure S4b) to be $0.075 \mathrm{mg} /$ $\mathrm{m}^{3}$ and $0.022 \mathrm{mg} / \mathrm{m}^{3}$ for Au control and nanospikes based QCMs, respectively. Additionally, the Au nanospikes were found to be highly stable for long periods of time under high temperatures compared to the widely-reported Au nano-dendrites as demonstrated in the supporting information (Figure S5). As such the Au control and Au nanospikes based QCMs were tested for their selectivity towards $\mathrm{Hg}^{0}$ vapor in industrial simulated process gas.

Long-term (industrial simulated) testing. To test the long-term performance of the Au control and nanospikes based QCMs, both were tested in a specially designed chamber and exposed to different $\mathrm{Hg}^{0}$ vapor concentrations $\left(\mathrm{C}_{1}=1.02 \mathrm{mg} / \mathrm{m}^{3}, \mathrm{C}_{2}=1.87 \mathrm{mg} / \mathrm{m}^{3}, \mathrm{C}_{3}\right.$ $=3.65 \mathrm{mg} / \mathrm{m}^{3}, \mathrm{C}_{4}=5.70 \mathrm{mg} / \mathrm{m}^{3}$ and $\mathrm{C}_{5}=10.55 \mathrm{mg} / \mathrm{m}^{3} \pm 0.05 \mathrm{mg} /$ $\mathrm{m}^{3}$ ) in the presence of six interferent gases (listed in Table 1) at an

\begin{tabular}{|c|c|}
\hline Interferent gas & Concentrationon \\
\hline $\begin{array}{l}\text { Humidity }\left(\mathrm{H}_{2} \mathrm{O}\right) \\
\text { Ammonia }\left(\mathrm{NH}_{3}\right) \\
\text { Acetaldehyde }\left(\mathrm{CH}_{3} \mathrm{CHO}\right) \\
\text { Acetone }\left(\mathrm{CH}_{3} \mathrm{COCH}_{3}\right) \\
\text { DMDS }\left(\mathrm{CH}_{3} \mathrm{SSCH}_{3}\right) \\
\text { Ethyl mercaptan }\left(\mathrm{C}_{2} \mathrm{H}_{5} \mathrm{SH}\right) \\
\text { MEK }\left(\mathrm{CH}_{3} \mathrm{C}(\mathrm{O}) \mathrm{CH}_{2} \mathrm{CH}_{3}\right)\end{array}$ & $\begin{array}{r}23.5 \mathrm{~g} / \mathrm{m}^{3} \\
270 \mathrm{mg} / \mathrm{m}^{3} \\
560 \mathrm{mg} / \mathrm{m}^{3} \\
18 \mathrm{mg} / \mathrm{m}^{3} \\
6 \mathrm{mg} / \mathrm{m}^{3} \\
20.2 \mathrm{mg} / \mathrm{m}^{3} \\
100 \mathrm{mg} / \mathrm{m}^{3}\end{array}$ \\
\hline
\end{tabular}

operating temperature of $101^{\circ} \mathrm{C}$ for a continuous period of 127 days. The interferent gas species and their concentrations were chosen to include VOCs that are present in industrial flue gases ${ }^{27-29}$ and/or known to have high affinity towards Au surfaces ${ }^{30-40}$. The longterm testing was designed to simulate the process conditions common found in minerals processing industries, such as those of an alumina refinery. In addition, high humidity $\left(>23 \mathrm{~g} / \mathrm{m}^{3}\right)$ and ammonia levels $\left(>0.25 \mathrm{~g} / \mathrm{m}^{3}\right)$ were used as they are commonly present in many mining processes and stack effluents. The QCMs were tested using two different test patterns during the 127 day period. The first test pattern in Figure 6a (referred to as the memory test) was designed to test for the memory effects the sensor may have when exposed to different concentrations of mercury vapor $\left(C_{n}\right)$ without the presence of any interferent gas species. The purpose of the second test pattern (referred to as interference test) was to test for the effects the interferent gases may have on the sensor response when sensing $\mathrm{Hg}^{\mathrm{O}}$ vapor in the presence of the gas species listed in Table 1. An example of an interference test at a $\mathrm{Hg}^{0}$ vapor concentration of $3.65 \mathrm{mg} / \mathrm{m}^{3}$ (or $\mathrm{C}_{3}$ ) is shown in Figure 6b. The clean $\mathrm{Hg}^{0}$ pulses are labeled with " $\mathrm{C}_{3}$ " while those performed in the presence of the interfering gases are labeled with "* $\mathrm{C}_{3}$ ". This test sequence was performed once for each of the five $\mathrm{Hg}^{0}$ vapor concentrations $\left(\mathrm{C}_{1}=1.02 \mathrm{mg} / \mathrm{m}^{3}, \mathrm{C}_{2}=\right.$ $1.87 \mathrm{mg} / \mathrm{m}^{3}, \mathrm{C}_{3}=3.65 \mathrm{mg} / \mathrm{m}^{3}, \mathrm{C}_{4}=5.70 \mathrm{mg} / \mathrm{m}^{3}$ and $\mathrm{C}_{5}=$ $10.55 \mathrm{mg} / \mathrm{m}^{3} \pm 0.05 \mathrm{mg} / \mathrm{m}^{3}$ ) tested. The desorption step in both test patterns involved exposing the sensors to dry $\mathrm{N}_{2}$ for a period of 1 hour without changing the operating temperature or the total flow rate, which was kept constant at $101 \pm 1^{\circ} \mathrm{C}$ and $200 \mathrm{sccm}$, respectively.

The data from the memory test was used to generate the sensor's calibration curves in order to analyze the data gathered from the interference tests. A combine analysis of both sets of data was used to determine the sensor's precision and repeatability performance over a given time period. The coefficient of variation $(\mathrm{CoV})^{41}$ method was used to estimate the precision of each sensor. The CoV is the ratio of the standard deviation to that of the mean of the sensor's response (spread of data) towards each $\mathrm{Hg}^{0}$ vapor concentration. For the set of pulses shown in Figure $6 \mathrm{~b}$, it was found that when exposed to $3.65 \mathrm{mg} / \mathrm{m}^{3}$ of $\mathrm{Hg}^{0}$ the $\mathrm{Au}$ control and nanospikes based sensors had a precision of $\pm 4.2 \%$ and $\pm 2.0 \%$, respectively over a 42 hour period (i.e. the number of pulses, $n=21$ ) regardless of the presence of the different interfering gas species. The precision of each sensor was found to improve with increasing $\mathrm{Hg}^{0}$ vapor concentration, where at $10.55 \mathrm{mg} / \mathrm{m}^{3}$ of $\mathrm{Hg}^{0}$ the $\mathrm{Au}$ control and nanospikes sensors were calculated to have a precision of $\pm 2.2 \%$ and $\pm 1.6 \%$, respectively. It can be observed in Figure $6 \mathrm{~b}$ that no temperature change is required, but only a nominal 1 hour $\mathrm{N}_{2}$ exposure for most of the mercury to be desorbed from the sensor surface and for the sensor to return to a common baseline equilibrium. It is noteworthy that the currently commercially available $\mathrm{Hg}^{0}$ vapor sensors based on gold film resistivity (Jerome 431-X) can measure $\mathrm{Hg}^{0}$ concentrations of up to only $0.999 \mathrm{mg} / \mathrm{m}^{3}$ with a precision of $\pm 5 \%$ at $0.10 \mathrm{mg} / \mathrm{m}^{3}$ and at 

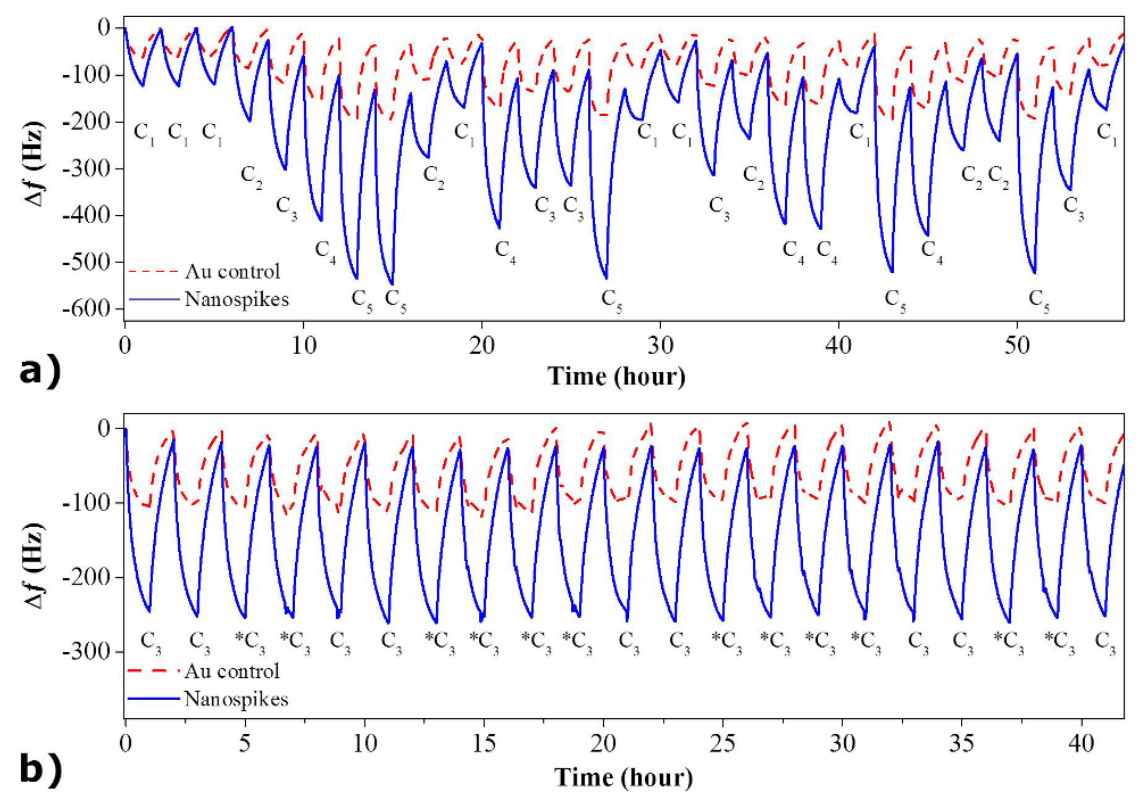

Figure 6 Response of the Au control and nanospikes based QCM during a (a) memory test and (b) interference test pattern. The exposed $\mathrm{Hg}^{0}$ vapor pulses in (a) were $C_{1}=1.02 \mathrm{mg} / \mathrm{m}^{3}, C_{2}=1.87 \mathrm{mg} / \mathrm{m}^{3}, C_{3}=3.65 \mathrm{mg} / \mathrm{m}^{3}, C_{4}=5.70 \mathrm{mg} / \mathrm{m}^{3}$ and $C_{5}=10.55 \mathrm{mg} / \mathrm{m}^{3} \pm 0.05 \mathrm{mg} / \mathrm{m}^{3} \mathrm{balanced} \mathrm{in} \mathrm{dry}$ $\mathrm{N}_{2}$. A total of five data points $(\mathrm{n}=5)$ was collected for each $\mathrm{Hg}^{0}$ vapor concentration from the memory test in (a) in order to generate a calibration curve. The ${ }^{*} \mathrm{C}_{3}$ in (b) refers to $\mathrm{Hg}^{0}$ vapor in the presence of interferent gas species listed in Table 1 . All desorption/recoveries were performed by exposure of dry $\mathrm{N}_{2}$ only and the operating temperature was kept constant at $101 \pm 1{ }^{\circ} \mathrm{C}$ throughout the 127 day continuous testing period.

an operating temperature up to only $40^{\circ} \mathrm{C}^{42}$. This clearly shows the superiority of these nanospikes based QCM sensors which have better precision over existing sensor technologies. Furthermore, the nanospikes structures were also found to be highly stable at and above the operating temperatures used in this study (refer to supporting information, Figure S5), making them viable as long lasting $\mathrm{Hg}^{0}$ vapor sensors.

In order to determine the accuracy of the Au control and nanospikes based $\mathrm{Hg}^{0}$ vapor sensors, a calibration curve was developed using the data from the memory tests. These calibration curves were used to estimate the $\mathrm{Hg}^{0}$ vapor concentrations reported by the sensor when performing the interference tests. When developing the calibration curve from the memory test, we found that the sensor response $(\Delta f)$ fitted closely with the three parameter LangmuirFreundlich model ${ }^{43}$ (refer to Figure 7 ) otherwise known as the loading ratio correlation (LRC) $)^{44}$. The coefficient of determination $\left(\mathrm{R}^{2}\right)$ was found to be $>0.99$ for all the fitted curves at $101^{\circ} \mathrm{C}$. The LRC model is given by;

$$
\Delta f=\frac{\Delta f_{m} \beta C^{\eta}}{1+\beta C^{\eta}}
$$

where $\Delta f_{m}, \beta$ and $\eta$ are the LRC model constants. The symbols $C$ represent the $\mathrm{Hg}^{0}$ vapor concentration and $\eta$ is a constant which is dependent on the sensitive layer's material property. In this case, $\Delta f_{\max }$ represents the sensor maximum response magnitude following saturation. The parameter $\beta$ is an indication of the range of $\mathrm{Hg}^{0}$ concentrations that may be detected prior to the sensor reaching saturation. A low $\beta$ indicates low dynamic range and saturation at low $\mathrm{Hg}^{0}$ concentrations. A high $\beta$ is preferred for a sensor with high precision in order to differentiate between small $\mathrm{Hg}^{0}$ vapor concentrations. The homogeneity of the mercury sorption sites on the $\mathrm{Au}$ surface is determined by the $\eta$ parameter. As $\eta$ approaches unity, the surface adsorption site energy distribution approaches homogeneity. It may be observed from equation (2) (or Figure $7 \mathrm{a}$ to $7 \mathrm{~d}$ ) that the sensitivity $(\partial(\Delta f) / \partial C)$ ) of the QCM based sensors towards $\mathrm{Hg}^{0}$ vapor at $101^{\circ} \mathrm{C}$ is concentration dependent; due to the slope of the LRC model (sensitivity) decreasing with increasing $\mathrm{Hg}^{0}$ vapor concentration. It was also observed that the $\mathrm{CoV}$ can be improved by using the sensor response from the recovery part rather than during the adsorption period of each sensing event. That is the CoV of the Au control and Au nanospikes at $\mathrm{A} \mathrm{Hg}^{0}$ concentration of $3.65 \mathrm{mg} / \mathrm{m}^{3}$ had improved to $3.4 \%$ (from $4.5 \%$ ) and $2.2 \%$ (from $11 \%$ ), respectively when using the recovery data rather than sorption data $(\Delta f)$. The improved precision obtained when using the recovery data over the $\mathrm{Hg}^{0}$ sorption data agrees well with our previous ${ }^{45}$ findings. Briefly, we had shown that $\mathrm{Hg}^{0}$ desorption has an activation energy which increases as the $\mathrm{Hg}^{0}$ coverage on the $\mathrm{Au}$ substrate decreases during the recovery period. Consequently, the amount of $\mathrm{Hg}^{0}$ desorbed is dependent on the amount of $\mathrm{Hg}^{0}$ sorption that occurs during the exposure period. Since the sensor recovery is performed by introducing dry nitrogen (no $\mathrm{Hg}^{0}$ or interferent gases) into the cell housing the sensors, the sensor reports the amount of $\mathrm{Hg}^{0}$ coming off the surface without being influenced by the interferent gases, thus resulting in increased precision during the recovery period.

The overall Au control and nanospikes based sensor performance during the 127 day testing period (using desorption data) are shown in Figures 8a and 8b, respectively. The data shown is the conversion of the QCM desorption response (shown in the supporting information, Figure S6) into a $\mathrm{Hg}^{0}$ vapor concentration using the calibration curve obtained from the memory test at the start of the 127 day experiment. A total of 140 data points $(n=140)$ from the desorption events was collected for each $\mathrm{Hg}^{0}$ vapor concentration tested with (n $=105)$ and without $(n=35)$ the presence of the interferent gas species during the long-term industry simulated testing period. It is observed that Au based QCMs in general work reasonably well as elemental $\mathrm{Hg}^{0}$ vapor sensors in the presence of interferent gas species, however, the nanospikes based QCM is observed to have a better dynamic range (enhanced differentiation between different $\mathrm{Hg}^{0}$ vapor concentrations) as well as higher sensitivity. The outstanding performance of the nanospikes is further highlighted by the fact that it was only calibrated at the start of the 127 day testing period, indicating that more precise data can be achieved by increasing the calibration interval during the 127 day test period.

The accuracy of the sensors was also evaluated by comparing the QCM reported $\mathrm{Hg}^{0}$ vapor concentrations' proximity to that of the concentrations obtained using the modified Ontario-Hydro method. 

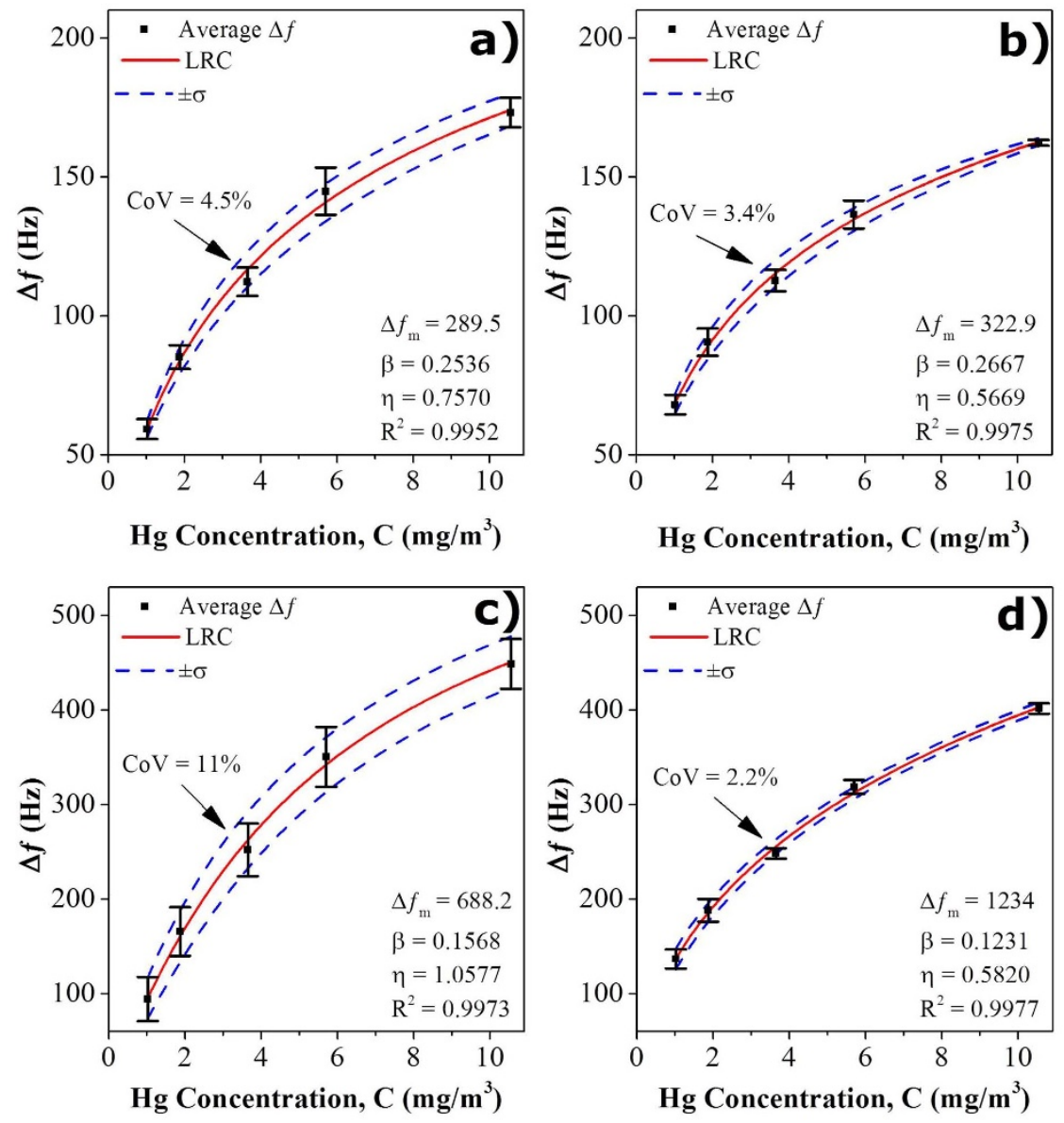

Figure 7 | Calibration curves based on loading ratio correlation (LRC) or Langmuir-Freundlich model derived from the memory test (a) sorption data of Au control, (b) sorption data of Au nanospikes, (c) desorption data of Au control and (d) desorption data of Au nanospikes at $101^{\circ} \mathrm{C}$. The number of data points for each $\mathrm{Hg}^{0}$ vapor concentration collected was five $(\mathrm{n}=5)$.

It was found that the nanospike sensor had more than an order of magnitude better accuracy than that of the Au control QCM at a $\mathrm{Hg}^{0}$ vapor concentration of $10.55 \mathrm{mg} / \mathrm{m}^{3}$ when allowing for only a $\pm 5 \%$ tolerance. That is, 8 and 82 (out of 140) data points reported by the Au control and nanospikes based QCMs, respectively, lied within the range of $10.55 \mathrm{mg} / \mathrm{m}^{3} \pm 5 \%$. This implies that the Au control and $\mathrm{Au}$ nanospikes based QCMs had an accuracy of $5.7 \%$ and $58.6 \%$, respectively. These accuracies are increased to $35 \%$ and $98 \%$ when the tolerance is increased to $\pm 15 \%$ (which is below the $\pm 20 \%$ required by the US-EPA RATA test guidelines ${ }^{46}$ ) for the Au control and Au nanospikes, respectively.

To summarize, we have shown that Au nanospikes directly electrodeposited onto a QCM sensor can act as an excellent microsensor for the detection of mercury vapor. The selective sensing capability of our developed nanospikes based sensing platform at elevated operating temperatures over a relatively large range of mercury vapor concentrations $\left(1\right.$ to $10 \mathrm{mg} / \mathrm{m}^{3}$ ) is extremely relevant to industrial effluent streams commonly found in the minerals processing sector. In addition, the sensor is able to report the $\mathrm{Hg}^{0}$ vapor concentration within a contaminated gas stream at least once every 2-hours (using the data from the desorption/recovery event) or once every hour (if both sorption and desorption data are used) as opposed to once every 2 -weeks with the currently accepted Ontario Hydro method ${ }^{10}$. The high operating temperature of $101^{\circ} \mathrm{C}$ reduces the effect of volatile organic and other compounds adsorbing on to the QCM sensitive layer while $\mathrm{Hg}^{0}$ vapor sorption on the sensitive layer is little reduced due to the high affinity between gold and mercury. The fact that the developed nanospikes QCM is little affected by the interferent gas species at $101^{\circ}$ means that no pretreatment of the gas mixture will be required before the introduction of industrial gas to the QCMs. This sensor could potentially be integrated in industrial processes as it would provide feedback to advanced process control technologies for efficient mercury removal and plant operation.

\section{Methods}

Optically polished At-cut QCM substrates $(7.5 \mathrm{~mm}$ diameter, $10 \mathrm{MHz}$ resonant frequency, Hy-Q Crystals, Australia) were deposited with a $10 \mathrm{~nm}$ Ti adhesion layer and $100 \mathrm{~nm} \mathrm{Au}$ (4.5 mm diameter) using e-beam evaporation on both sides of the QCM. The surfaces of these QCM substrates were further modified by electrodeposition. The electrodeposition process was performed using a CH Instruments (CHI 760C) electrochemical analyzer in an electrochemical cell that allowed reproducible position of the working ( $\mathrm{Au} \mathrm{QCM}$ ), auxiliary (graphite) and reference ( $\mathrm{Ag} / \mathrm{AgCl} 3 \mathrm{M}$ $\mathrm{KCl})$ electrodes and a nitrogen inlet tube. The electrolyte solution contained hydrogen tetrachloroaurate(III) tri-hydrate $(2.718 \mathrm{~g} / \mathrm{L})$ and lead(II) acetate tri-hydrate $(0.177 \mathrm{~g} / \mathrm{L})$ (Sigma-Aldrich, Australia), the cyclic voltammetry profile of which is shown in the supporting information (Figure S7). The deposition potential was kept constant at $0.05 \mathrm{~V}$ with varying deposition times $(50,100,200,300,400,500,600,700$ and $800 \mathrm{sec}$ ). A separate Au-QCM crystal was used each time for Au electrodeposition at different time points. The electrochemical surface area (ESA) of each sample was determined by performing cyclic voltammetry (CV) of Au control and $\mathrm{Au}$ nanospikes at $100 \mathrm{mVs}^{-1}$ in $1 \mathrm{M} \mathrm{H}_{2} \mathrm{SO}_{4}$.

Following electrodeposition, the QCMs were washed several times with deionized water, air-dried, and characterized using scanning electron microscopy (SEM), X-Ray diffraction (XRD), and energy-dispersive X-ray spectroscopy (EDX). SEM and EDX measurements were performed on a Nano-SEM instrument operating at an accelerating voltage of $10 \mathrm{kV}$. X-ray photoelectron spectroscopy (XPS) characterization of the materials was performed using a Thermo K-Alpha instrument at a pressure better than $1 \times 10^{-9}$ Torr. The core level binding energies (BEs) were aligned with the adventitious $\mathrm{C} 1 \mathrm{~s}$ binding energy of $285 \mathrm{eV}$. XRD measurements were carried out on a Bruker D8 Discover micro diffraction system with general area detector diffraction system (GADDS) instrument operating at a voltage of $40 \mathrm{kV}$ and a current of $40 \mathrm{~mA}$ with $\mathrm{Cu} \mathrm{K} \alpha$ radiation. The 600 sec electrodeposited QCM (referred to as nanospikes) was pre-treated under dry nitrogen gas at $150^{\circ} \mathrm{C}$ for a period of two days. Thereafter, 

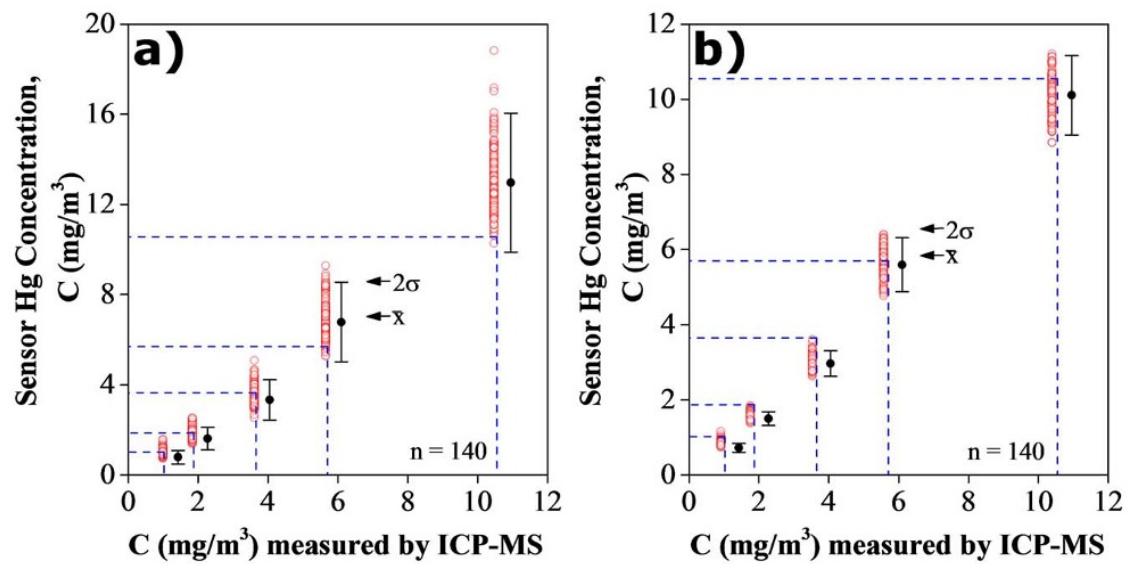

Figure 8 $\mid$ QCM response magnitudes from a 127 day continuous test (desorption data only) for (a) Au-control and (b) nanospikes base sensors. The QCM response magnitude for each sensor is converted to $\mathrm{Hg}^{0}$ vapor concentration (y-axis) and compared to the delivered $\mathrm{Hg}^{0}$ vapor concentration (x-axis). The QCMs were exposed towards different $\mathrm{Hg}^{0}$ vapor concentrations with/without the presence of interferent gas species over a continuous 127 day testing period at $101^{\circ} \mathrm{C}$, simulating industrial conditions. The $\mathrm{n}$ values indicate the number of data points collected for each $\mathrm{Hg}$ concentration.

the Au nanospikes along with the unmodified Au based QCM (refered to as Au control) were tested for their sensing capabilities towards a dynamic range of mercury vapors at two different operating temperatures of 28 and $101 \pm 1^{\circ} \mathrm{C}$. The mercury concentrations towards which the sensors were tested at were $\mathrm{C}_{1}=1.02 \mathrm{mg} / \mathrm{m}^{3}, \mathrm{C}_{2}=$ $1.87 \mathrm{mg} / \mathrm{m}^{3}, \mathrm{C}_{3}=3.65 \mathrm{mg} / \mathrm{m}^{3}, \mathrm{C}_{4}=5.70 \mathrm{mg} / \mathrm{m}^{3}$ and $\mathrm{C}_{5}=10.55 \mathrm{mg} / \mathrm{m}^{3} \pm 0.05 \mathrm{mg} /$ $\mathrm{m}^{3}$ balanced in dry $\mathrm{N}_{2}$. As the amount of mercury sorption is higher at $28^{\circ} \mathrm{C}$ relative to $101^{\circ} \mathrm{C}^{45}$, the operating temperature of $28^{\circ} \mathrm{C}$ was chosen for experiments which determine whether the higher sensitivity of the modified surfaces were due to increased ESA. The operating temperature of $101^{\circ} \mathrm{C}$ was chosen for long term testing experiments ${ }^{16}$ as it is a representative of temperatures used in field sampling of trace amounts of $\mathrm{Hg}^{0}$ in industrial effluents $\mathrm{s}^{25}$. This relatively higher operating temperature reduces the interferenct effects from other gases such as VOCs and humidity as well as enabling the use of the developed sensor for most industrial processes.

$\mathrm{Hg}^{0}$ permeation tubes (VICI, TX, USA) were used to generate various concentrations of $\mathrm{Hg}^{0}$ vapors in a highly controlled manner. $\mathrm{Hg}^{0}$ vapor concentrations in the test stream were calibrated using an acidic $\mathrm{KMnO}_{4}$ impinger train system (similar to EPA's Ontario Hydro method) and their analysis conducted by inductively coupled plasma mass spectroscopy (ICP-MS). This calibration method was used on a regular basis to ensure that correct $\mathrm{Hg}^{0}$ vapor concentrations were generated over the entire 127 day testing period. ICP-MS measurements were performed using a HP4500 series 300, ShieldTorch System. An Agilent (53131A) frequency counter with a resolution of $\pm 0.1 \mathrm{~Hz}$ over an integration period of $4 \mathrm{sec}$ was used to measure the resonant frequency $(f)$ of the QCMs.

All sensing measurements were conducted using the following procedure: The experiments were performed in duplicates in a custom built gas cell, which housed 4 QCM sensors (2 each of nanospikes and Au control), and exposed to a gas stream containing a mixture of $\mathrm{N}_{2}$ and a known concentration of $\mathrm{Hg}^{0}$ vapor (with or without interferent gases) for 1 hour. Thereafter, the sensors were regenerated by $\mathrm{N}_{2}$ flow alone for 1 hour without altering the total flow in the gas cell or the operating temperature. Both sets of sensors were tested in a specially designed sensor chamber. The sensors were tested towards $\mathrm{Hg}^{0}$ vapor in the presence of additional interferent gases (listed in Table 1) including volatile organic compounds (VOCs) that are known to have high affinity with $\mathrm{Au}^{30-40}$ or to be present in most industrial flue gases ${ }^{27-29}$. Throughout the experiments, the total gas flow rate $\left(\mathrm{N}_{2}+\mathrm{Hg}^{0}, \mathrm{Hg}^{0}+\right.$ interferent gas species or $\mathrm{N}_{2}$ alone) was kept constant at $200 \mathrm{sccm}$ using a specially developed multichannel gas delivery system, employing mass flow controllers (MKS instruments, Inc. USA). The humidity level $\left(23.5 \mathrm{~g} / \mathrm{m}^{3}\right)$ was generated using a relative humidity generator (V-Gen from InstruQuest). This humidity level was equivalent to testing a stream with a $\mathrm{RH}$ value of above $100 \%$ at $50^{\circ} \mathrm{C}$ once accounting for the $1: 3$ dilution factor employed during the experiments.

1. Qui, J. Tough talk over mercury treaty. Nature 493, 144-145 (2013).

2. Gardner, E. Peru battles the golden curse of Madre de Dios. Nature 486, 306-307 (2012).

3. Canstein, H. V., Kelly, S., Li, Y. \& Wagner-Dobler, I. Species Diversity Improves the Efficiency of Mercury-Reducing Biofilms under Changing Environmental Condtions. Appl. Environ. Microbiol. 68, 2829-2837 (2002).

4. Schrope, M. US to take temperature of mercury threat. Nature 409, 124-124 (2001).

5. Laudal, D. L. \& French, N. B. State-Of-The-Art Of Mercury Continuous Emission Monitors For Coal-Fired Systems. Conference On Air Quality II: Mercury 2, 1-16 (2000).

6. Weissberg, B. G. Determination of Mercury in Soils by Flameless Atomic Absorption Spectrometry. Econ. Geol. 66, 1042-1047 (1971).
7. Windham, R. L. Simple device for compensation of broad-band absorption interference in flameless atomic absorption determination of mercury. Anal. Chem. 44, 1334-1336 (1972).

8. Sholupov, S., Pogarev, S., Ryzhov, V., Mashyanov, N. \& Stroganov, A. Zeeman atomic absorption spectrometer RA-915 + for direct determination of mercury in air and complex matrix samples. Fuel Process. Technol. 85, 473-485 (2004).

9. Logar, M., Horvat, M., Akagi, H. \& Pihlar, B. Simultaneous determination of inorganic mercury and methylmercury compounds in natural waters. Anal. Bioanal. Chem. 374, 1015-1021 (2002).

10. Laudal, D. L., Thompson, J. S., Pavlish, J. H., Brickett, L. A. \& Chu, P. Use of continuous mercury monitors at coal-fired utilities. Fuel Process. Technol. 85 , 501-511 (2004).

11. Sauerbrey, G. Verwendung von Schwingquarzen zur Wägung dünner Schichten und zur Mikrowägung. Z. Phys. A: Hadrons Nucl. 155, 206-222 (1959).

12. Rand, D. A. J. \& Woods, R. The nature of adsorbed oxygen on rhodium, palladium and gold electrodes. J. Electroanal. Chem. 31, 29-38 (1971).

13. Plowman, B. et al. Gold nanospikes formed through a simple electrochemical route with high electrocatalytic and surface enhanced Raman scattering activity. Chem. Commun. 7, 5039-5041 (2009).

14. George, M. A. \& Glaunsinger, W. S. The electrical and structural properties of gold films and mercury-covered gold films. Thin Solid Films 245, 215-224 (1994).

15. Sabri, Y. M. et al. Mercury diffusion in gold and silver thin film electrodes on quartz crystal microbalance sensors. Sens. Actuators, B 137, 246-252 (2009).

16. Sabri, Y. M. et al. Creating gold nanoprisms directly on quartz crystal microbalance electrodes for mercury vapor sensing. Nanotechnology 22, 305501-305509 (2011)

17. Sun, X., Dong, S. \& Wang, E. High-Yield Synthesis of Large Single-Crystalline Gold Nanoplates through a Polyamine Process. Langmuir 21, 4710-4712 (2005).

18. Schultze, J. W. \& Dickertmann, D. Potentiodynamic desorption spectra of metallic monolayers of $\mathrm{Cu}, \mathrm{Bi}, \mathrm{Pb}, \mathrm{Tl}$, and $\mathrm{Sb}$ adsorbed at (111), (100), and (110) planes of gold electrodes. Surf. Sci. 54, 489-505 (1976).

19. Cao, L., Zhu, T. \& Liu, Z. Formation mechanism of nonspherical gold nanoparticles during seeding growth: Roles of anion adsorption and reduction rate. J. Colloid Interface Sci. 293, 69-76 (2006).

20. O’Mullane, A. P., Ippolito, S. J., Sabri, Y. M., Bansal, V. \& Bhargava, S. K. Premonolayer Oxidation of Nanostructured Gold: An Important Factor Influencing Electrocatalytic Activity. Langmuir 25, 3845-3852 (2009).

21. Goeders, K. M., Colton, J. S. \& Bottomley, L. A. Microcantilevers: Sensing Chemical Interactions via Mechanical Motion. Chem. Rev. 108, 522-542 (2008).

22. Lavrik, N. V., Sepaniak, M. J. \& Datskos, P. G. Cantilever transducers as a platform for chemical and biological sensors. Rev. Sci. Instrum. 75, 2229-2253 (2004).

23. Morris, T., Sun, J. \& Szulczewski, G. Measurement of the chemical and morphological changes that occur on gold surfaces following thermal desorption and acid dissolution of adsorbed mercury. Anal. Chim. Acta 496, 279-287 (2003).

24. Fialkowski, M., Grzeszczak, P., Nowakowski, R. \& Holyst, R. Absorption of Mercury in Gold Films and Its Further Desorption: Quantitative Morphological Study of the Surface Patterns. J. Phys. Chem. B 108, 5026-5030 (2004).

25. Levlin, M., Niemi, H. E. M., Hautojärvi, P., Ikävalko, E. \& Laitinen, T. Mercury adsorption on gold surfaces employed in the sampling and determination of vaporous mercury: a scanning tunneling microscopy study. Fresenius J. Anal. Chem. 355, 2-9 (1996).

26. Larjava, K., Laitinen, T., Kiviranta, T., Siemens, V. \& Klockow, D. Application of the diffusion screen technique to the determination of gaseous mercury and mercury (II) chloride in flue gases. Int. J. Environ. Anal. Chem. 52, 65-73 (1993).

27. Forster, P. G. \& Grocott, S. C. Alumina Refinery Odour. Proceedings of the $4^{\text {th }}$ International Alumina Quality Workshop, 478-487 (1996). 
28. Mullett, M., Tardio, J., Bhargava, S. \& Dobbs, C. Removal of mercury from an alumina refinery aqueous stream. J. Hazard. Mater. 144, 274-282 (2007).

29. Mullett, M. E. Mercury Removal from Bayer Refinery Condensate thesis, RMIT University, (2005), < http://researchbank.rmit.edu.au/eserv/rmit:6149/mullett. pdf $>$, date of access: 01/08/2014.

30. Bilic, A., Reimers, J. R., Hush, N. S. \& Hafner, J. Adsorption of ammonia on the gold (111) surface. J. Chem. Phys. 116, 8981-8987 (2002).

31. Tanida, K. \& Hoshino, M. Contiuous determination of mercury in air by gold amalgamation and flameless. The Rigaku Journal 7, 35-40 (1990).

32. Finklea, H. O., Avery, S., Lynch, M. \& Furtsch, T. Blocking oriented monolayers of alkyl mercaptans on gold electrodes. Langmuir 3, 409-413 (2002).

33. Rocha, T. A. P., Gomes, M. T. S. R., Duarte, A. C. \& Oliveira, J. A. B. P. Quartz crystal microbalance with gold electrodes as a sensor for monitoring gas-phase adsorption/desorption of short chain alkylthiol and alkyl surfides. Anal. Commun. 35, 415-416 (1998).

34. Richton, R. E. \& Farrow, L. A. Adsorption kinetics of ammonia on an inhomogeneous gold surface. J. Phys. Chem. 85, 3577-3581 (2002).

35. Kay, B. D., Lykke, K. R., Creighton, J. R. \& Ward, S. J. The influence of adsorbate-absorbate hydrogen bonding in molecular chemisorption: $\mathrm{NH}_{3}, \mathrm{HF}$, and $\mathrm{H}_{2} \mathrm{O}$ on $\mathrm{Au}(111)$. J. Chem. Phys. 91, 5120-5121 (1989).

36. Surplice, N. A. \& Brearley, W. The adsorption of carbon monoxide, ammonia, and wet air on gold. Surf. Sci. 52, 62-74 (1975).

37. Nuss, $\mathrm{H}$. \& Jansen, M. $\left[\mathrm{Rb}\left([18]\right.\right.$ crown-6) $\left.\left(\mathrm{NH}_{3}\right)_{3}\right] \mathrm{Au} \cdot \mathrm{NH}_{3}$ : Gold as Acceptor in $\mathrm{N}-\mathrm{H} \cdots \mathrm{Au}^{-}$Hydrogen Bonds. Angew. Chem. 45, 4369-4371 (2006).

38. de Vooys, A. C. A. et al. The nature of chemisorbates formed from ammonia on gold and palladium electrodes as discerned from surface-enhanced Raman spectroscopy. Electrochem. Commun. 3, 293-298 (2001).

39. Mirsky, V. M. et al. Self-assembled monolayers as selective filters for chemical sensors. Nanotechnology 13, 175-178 (2002).

40. Meyer, R., Lemire, C., Shaikhutdinov, S. K. \& Freund, H. Surface chemistry of catalysis by gold. Gold Bull. 37, 72-124 (2004).

41. Reed, G. F., Lynn, F. \& Meade, B. D. Use of Coefficient of Variation in Assessing Variability of Quantitative Assays. Clin. Diagn. Lab. Immunol. 9, 1235-1239 (2002).

42. Elemental Services \& Consulting Inc. Mercury Vapor Analyzer Comparison, $<$ http://escoinfo.com/pdf_07/MVA's.pdf>, date of access: 01/05/2009.

43. Yao, C. Extended and improved Langmuir equation for correlating adsorption equilibrium data. Sep. Purif. Technol. 19, 237-242 (2000).

44. Kapoor, A., Ritter, J. A. \& Yang, R. T. An Extended Langmuir Model for Adsorption of gas Mixtures on Heterogeneous Surfaces. Langmuir 6, 660-664 (1990)
45. Sabri, Y. M., Ippolito, S. J., Tardio, J. \& Bhargava, S. K. Study of Surface Morphology Effects on Hg Sorption-Desorption Kinetics on Gold Thin-Films. J. Phys. Chem. C. 116, 2483-2492 (2012).

46. Laudal, D. L. Conducting a RATA of continuous mercury monitors using EPA Method 30B. Fuel Process. Technol. 90, 1343-1347 (2009).

\section{Acknowledgments}

Authors acknowledge the Australian Research Council (ARC) for supporting this project (LP100200859, DP0988099) and the RMIT microscopy and microanalysis facility (RMMF) for allowing the use of their comprehensive facilities and services. SI and VB acknowledge ARC for APDI (LP100200859) and Future Fellowships (FT140101285), respectively. The authors thank Dr Jeff Huges for fruitful discussions and Mr Cao Yuxun and Paul Morrison for their technical support.

\section{Author contributions}

Y.M.S. and S.J.I. carried out the experiments. A.P.O. carried out some of the electrochemical experiments. Y.M.S., S.J.I., J.T., V.B., A.P.O. and S.K.B. analysed the data, contributed to data interpretation and manuscript writing. S.K.B. supervised the research.

\section{Additional information}

Supplementary information accompanies this paper at http://www.nature.com/ scientificreports

Competing financial interests: The authors declare no competing financial interests.

How to cite this article: Sabri, Y.M. et al. Gold nanospikes based microsensor as a highly accurate mercury emission monitoring system. Sci. Rep. 4, 6741; DOI:10.1038/srep06741 (2014).

This work is licensed under a Creative Commons Attribution-NonCommercialShareAlike 4.0 International License. The images or other third party material in this article are included in the article's Creative Commons license, unless indicated otherwise in the credit line; if the material is not included under the Creative Commons license, users will need to obtain permission from the license holder in order to reproduce the material. To view a copy of this license, visit http:// creativecommons.org/licenses/by-nc-sa/4.0/ 